\title{
Novel insights on the possible effects of water exposure on the structural integrity of the perineum during a waterbirth
}

\author{
Dimitrios Papoutsis ${ }^{1}$
}

\section{Dear Editor,}

The effects of water immersion on the skin and anatomical structures of the perineum have been reported to be conflicting with reports of increased, unchanged or reduced rates of obstetric perineal trauma. A second-degree perineal trauma refers to the disruption of the perineal muscles and the rectovaginal fascia, and could result in pelvic organ prolapse and may have a negative effect on the individual's sexual function ${ }^{1,2}$. For those studies reporting that a waterbirth may be protective of a second-degree tear, it has been proposed that the underlying mechanisms involve the buoyancy effect of water that reduces the weight of the infant upon delivery ${ }^{3}$, the positive effect of warmth resulting in vasodilation and increased perineal blood supply ${ }^{4}$, and a more conservative management of birth with more spontaneous pushing and a slower delivery ${ }^{5}$.

The Cochrane Database systematic review published in 2018 showed that water immersion during labour and birth had little effect on the occurrence of third-and fourthdegree perineal tears $(\mathrm{RR}=1.36 ; 95 \% \mathrm{Cl}: 0.85-2.18)^{6}$. Third- and fourth-degree perineal tears involve the anal sphincter complex and represent the primary risk factor for the development of anal incontinence ${ }^{6}$. The Cochrane review concluded that the availableto-date evidence is of moderate to low-quality and further research is required in order to draw more definite conclusions.

On the other hand, there are reports from observational studies that there is an increased risk for anal sphincter rupture in waterbirths ${ }^{7}$. There are studies in the literature that have investigated the possible effects of water exposure on the tissue integrity of other areas of the body than the perineum. It has been reported that water exposure to the plantar skin has a 'water-logging' negative effect on its biophysical properties and can lead to softening of the skin after 45 minutes of water immersion ${ }^{8}$. In another report, water exposure of the forearm skin for 3 hours led to changes in the skin permeability and ultrastructure of the stratum cornea which represents the outer skin layer, with morphological changes in the intercellular spaces and increased water content throughout the $\operatorname{skin}^{9}$. When the threshold hydration of $85 \%$ relative humidity is reached then abrupt changes have been observed in the molecular properties of the skin that coincide with changes in the macroscopic swelling properties as well as the mechanical qualities of the outer skin layers ${ }^{10}$. Others have found that high hydration levels of the skin may result in the formation of a lightly cross-linked network of collagen leading to a less tensile strength of the skin ${ }^{11}$. Moreover, prolonged exposure to water may lead to the formation of inter- and intra-cellular aqueous inclusions within the skin ${ }^{12}$. It has been calculated that the amount of mechanical stress required to cause the same level of skin deformation decreases up to three orders of magnitude with the increase in skin hydration as a result of prolonged exposure to water ${ }^{11}$. This means that less mechanical force is required for the skin to give way and tear after being exposed to water.

The above reported physiological mechanisms might explain why some women giving birth in the water have less chances of an intact perineum when compared to a dry-land birth $^{13}$. They may also explain why nulliparous women having a waterbirth when compared to multiparous have a higher risk of severe perineal trauma as they may potentially stay longer in the water. Further research is needed to clarify these hypotheses as to the effects of water exposure on the perineum during a waterbirth. Thus, it is suggested that any future research design should include taking tissue samples from the perineum and investigating their qualitative and quantitative properties as a function of time of water exposure.

\section{AFFILIATION \\ 1 Department of Midwifery, University of Western Macedonia, Ptolemaida, Greece \\ CORRESPONDENGE TO \\ Dimitrios Papoutsis. School of Health Sciences, Department of Midwifery, University of Western Macedonia, Ptolemaida, 50200, Greece. E-mail: dpapoutsis@ nowm.gr}

\section{KEYWORDS}

waterbirths, perineum, skin, obstetric anal sphincter injuries

Received: 1 August 2020

Accepted: 4 September 2020 


\section{REFERENGES}

1. Mustain WC. Functional Disorders: Rectocele. Clin Colon Rectal Surg. 2017;30(1):63-75. doi:10.1055/s-0036-1593425

2. Signorello LB, Harlow BL, Chekos AK, Repke JT. Postpartum sexual functioning and its relationship to perineal trauma: a retrospective cohort study of primiparous women. Am J Obstet Gynecol. 2001;184(5):881-890. doi:10.1067/mob.2001.113855

3. Ulfsdottir H, Saltvedt S, Georgsson S. Women's experiences of waterbirth compared with conventional uncomplicated births. Midwifery. 2019;79:102547. doi:10.1016/j.midw.2019.102547

4. Aasheim V, Nilsen ABV, Reinar LM, Lukasse M. Perineal techniques during the second stage of labour for reducing perineal trauma. Cochrane Database Syst Rev. 2017;6(6):CD006672. doi:10.1002/14651858.CD006672.pub3

5. Garland D. Revisiting waterbirth: an attitude to care. London, United Kingdom: Palgrave Macmillan; 2010.

6. Cluett ER, Burns E, Cuthbert A. Immersion in water during labour and birth. Cochrane Database Syst Rev. 2018;5(5):CD000111. doi:10.1002/14651858.CD000111.pub4

7. McPherson KC, Beggs AD, Sultan AH, Thakar R. Can the risk of obstetric anal sphincter injuries (OASls) be predicted using a risk-scoring system?. BMC Res Notes. 2014;7(1):471. doi:10.1186/1756-0500-7-471

8. Schmidt D, Germano AMC, Milani TL. Effects of water immersion on sensitivity and plantar skin properties. Neurosci Lett. 2018;686:41-46. doi:10.1016/j.neulet.2018.08.048

9. Ogawa-Fuse C, Morisaki N, Shima K, et al. Impact of water exposure on skin barrier permeability and ultrastructure. Contact Dermatitis. 2019;80(4):228-233. doi:10.1111/cod.13174

10. Mojumdar EH, Pham QD, Topgaard D, Sparr E. Skin hydration: interplay between molecular dynamics, structure and water uptake in the stratum corneum. Sci Rep. 2017;7(1):15712. doi:10.1038/s41598-017-15921-5

11. Kalra A, Lowe A, Jumaily AAl. An Overview of Factors Affecting the Skin's Young's Modulus. J Aging Sci. 2016;4(2):156161. doi:10.4172/2329-8847.1000156

12. Albèr C, Brandner BD, Björklund S, Billsten P, Corkery RW, Engblom J. Effects of water gradients and use of urea on skin ultrastructure evaluated by confocal Raman microspectroscopy. Biochim Biophys Acta. 2013;1828(11):2470-2478. doi:10.1016/j.bbamem.2013.06.011

13. Papoutsis D, Antonakou A, Gornall A, Tzavara C. The incidence of and predictors for severe perineal trauma and intact perineum in women having a waterbirth in England: A hospital-based study. J Womens Health (Larchmt). 2020. doi:10.1089/jwh.2019.8244

\section{CONFLICTS OF INTEREST}

The author has completed and submitted the ICMJE Form for Disclosure of Potential Conflicts of Interest and none was reported.

\section{FUNDING}

There was no source of funding for this research.

\section{PROVENANCE AND PEER REVIEW}

Not commissioned; internally peer reviewed. 